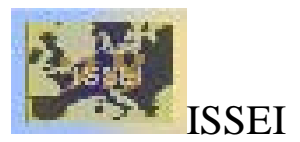

International Society for the Study of European Ideas

in cooperation with the University of Cyprus

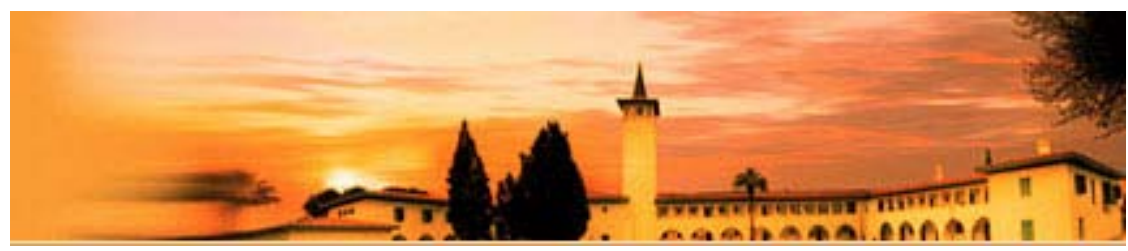

\title{
THE DIALOGUE BETWEEN PHILOSOPHY AND LITERATURE
}

\section{Olga Mazurina}

Co-professor of the Russian State University (Moscow, Russia)

Section V: Religion, Philosophy, Anthropology, Psychology, Language

Workshop Title: Philosophical Narrative Confronted with the Challenge of Post metaphysical Thinking

\begin{abstract}
The talk about the relationship between literature, philosophy, history and science crops again and again and is found in the works by modern philosophers such as Richard Rorty, Arthur Danto and some others as well as by literary critics, for example Wolfgang Iser. Some of them see the boundary between philosophy and literature while others dismiss it. Many philosophers believe that a true philosophical insight is best served 'au naturele'; style should not overtake the message. On the other hand, we could remember classical examples of philosophers whose literary style has become indispensable to the philosophical success. In my report I would like to discuss R. Rorty's view on the problem, his understanding of representation and the critical approach to his view.
\end{abstract}

Key Words: philosophy, literature, style, message, argument, reality, fiction, world-view.

\section{Introduction}

My paper focuses on some aspects of the relationship between philosophy and literature and is based on the ideas expressed by Serge Grigoriev from Ithaca College, New-York who studied Richard Rorty’s views on the problem. 
The talk about the relationship between philosophy and literature is an old affair, which usually makes philosophers somewhat uncomfortable. One of the reasons is the vagueness of terms employed. There is no such thing as a unified and uniform philosophical tradition; there are no writers who are only writers and philosophers who are only philosophers. Philosophers are also writers; just as writers sometimes put forth some philosophical propositions. There are a fair number of examples to prove it. However, there is a clear split within philosophy between those who see the boundary between philosophy and literature as real, and those who dismiss it as a mere misconceived artifact of our cultural history.

Thus there are many philosophers who believe that a true philosophical insight is best served au naturele, that it stands in no need of an artful stylistic embellishment. In fact the superior literary quality of one's prose may be frequently taken as a disguise for poor argument.

The "traditional” philosophers usually apprehend literary quality of written philosophical works. They think that philosophy has its own distinct priorities and that the questions of style should be regulated; style should not overtake the message. In other words - and this is important - the tradition regards philosophy, first and foremost, as a species of argument and not as a species of literary writing.

Once we grant that literature and philosophy aim at accomplishing different things, it follows that they will employ rather different means to achieve their goals.

On the other hand, there are philosophers who believe that the use of literary style can become indispensable to the philosophical success of a project. An example may be the classical study of Nietzsche by Alexander Nehamas. Style, considered from a literary point of view may be very central to and individual philosopher's sense of self.

We can find many names, e.g. Ralf Waldo Emerson, George Santayana, Iris Murdock, Leo Tolstoy, Fyodor Dostoyevsky and many others, in the lists of both writers and philosophers. Think of dazzling fluency of Bernard Russell’s prose in his History of Western Philosophy.

\section{Similarities and distinctions between philosophy and literature.}

Further, I'd like to dwell on some views of similarities and distinctions between philosophy and literature.

First, both philosophy and literature try to represent or portray reality. They both tell us something about it, but neither leads to a disclosure of new aspects of the empirical world. The task of philosophy is not so much to establish how things are in themselves, but to find new ways of explaining them and responding to them within the context of our beliefs and ordinary practices. Thus, despite its occasional employment of technical language, philosophy remains ultimately grounded in the common sense and social interests. As such it can be seen as 
exploring the possibilities inherent in our language or mind for more productive engagement with the world around us, instead of exploring the world itself.

In this regard philosophy does resemble literature; for both stage what they are worth entertaining, instead of locating or identifying it in the outside world.

Second, both philosophy and literature are inherently dramatic in character and staging is perhaps the only appropriate form for rendering it manifest. In philosophy, just as in literature, the staging of dramatic confrontation (between concepts or between people) is the primary mode of disclosure of the intended contents, the primary form in which the explanation establishes itself before the reader.

Third, outstanding philosophers, e.g. Francis Bacon, Friedrich Nietzsche and others, pointed to imaginative nature of the philosophical enterprise. Both philosophy and literature are permitted to explore and delight in the possibilities located in the proximate possible worlds.

However, philosophy and literature are quite different when it comes to the kind of possibilities involved. The counterfactual states of affairs which philosophers explore stand in clear logical relationships to the states of affairs that we actually believe to obtain in reality; the purpose of such thought-experiments is to expose certain relationships characteristic of our world, by showing how they would be modified had our world been different in some determinate respects. Although philosophy does draw on an imaginative, constructive element, it is also a norm-governed discourse which allows certain possibilities and rejects others as incoherent. Therefore, it can be maintained that the possibilities philosophers explore are, in some sense, real, as opposed to being merely fanciful. In this connection we can remember Karl Popper's view that the world of the logical contents of our culture may contain things as yet unthought but real nonetheless - real because discoverable within the expanding horizon of our culture. On the other hand, the world of a fictional tale is usually parasitic on some ordinary account of reality, but the unusual possibilities it introduces need not stand in any determinate logical relationship with the conditions obtaining in the world as we know it - the only requirement is that these possibilities be readily imaginable.

Fourth, the point is how philosophical and literary works are found relevant and are evaluated. The appeal and relevance of philosophical works does not depend solely on its internal coherence, but also on its perceived accuracy, as judged by the standards of the empirically encountered world. Philosophers routinely address and employ the results obtained in special sciences; and the best professionals in the field generally follow the guidelines for evaluating the credibility of such external evidence that are not different from those used by the scientists. 
Literature, on the other hand, while it is perfectly capable of playfully drawing on the normatively invested frameworks of other discourses, and assimilating them to its own purposes, does not have a set normative framework of its own. More importantly, in evaluating a work of literature it is appropriate to carry at least equal weight with considerations about the content. Thus, on literary terms, it is not at all preposterous to aspire to write a work held together exclusively by the force of its style, in the process dismissing the content-governing norms altogether. In philosophy, that would be an unusual aspiration.

Even Nietzsche's work, despite his stylistic preoccupations, remains at least as much content-driven as it is driven by literary considerations.

The last fifth point deals with the engagement of a reader into the conflict of the work. Wolfgang Iser, a literary critic, says that literature "simulates life, not in order to portray it, but in order to allow the reader to share it”. In other words, literature stages a conflict into which it allows the readers to enter, as they are guided by the implicit instructions supplied by the text. Usually, it is a conflict between characters; but it can also be a play of conflicting styles, or aesthetic forms; or a play of absences, or a struggle to express or fix that which slips through one's fingers. The purpose of this game of literature, according to Iser, is that "it allows us to simulate an inexhaustible variety of trial runs, far in excess of what life may demand of us”.

Novels usually do not do with the objective universe, but more with the universe of motivations, existential conflicts, possibilities and limitations. Something like that is often described by the word "world-view". Such conceptual structures circulate in human communities, provoking discussions, criticisms and comments. Virtually every world-view gives rise to its own conflicts supplying the dynamic mechanism of the novel's background.

Philosophy has long been in the business of articulating different world views. As Nietzsche proclaims "the goal of every philosophical view is to present a picture of the world and a conception of values which makes a certain type of person possible and which allows it to prosper and flourish. And, indeed, there are many philosophers who consider it an essential part of their labour to understand how the world that emerges from the studies of science and history could meaningfully accommodate the interests and strivings of a thinking and sentient human person. The obvious examples of this are found in classical American philosophy, especially the pragmatists. Figures like Popper and Collingwood, Hegel and Kant also come to mind, in fact, any systematic philosopher who attempted to link epistemology, metaphysics, and moral theory or theory of social justice.

However, it is precisely philosophers' aspiration to play special role in shaping our vision of reality. The analysis of the rational structure of a belief system opens a way to conceptual innovation. In this sense, philosophy is like theoretical mechanics: it idealizes, it works with 
abstractions, and, on its own, it does not enable one to build a bridge; however, the conceptual insight it generates can stimulate the practically applied thought to seek solutions in the directions that, prior to such analysis, did not appear particularly promising.

\section{Conclusion}

To sum up, I would like to turn to Rorty's idea of reducing philosophy to literature in his earlier works. In his later works he gives the solution not to reduce it to literature, but to learn how to balance "the quasi-person, the hypostasized and personalized concept, with the empirical facts about people of flesh and blood”. In his work Truth and Progress he describes his late change of heart as a willingness to 'put a leash' on his nominalism.

\section{References:}

Grigoriev, Serge. Theory and Fiction: Rorty’s View of Philosophy as Literature. The European Legacy, Vol. 16, \# 1, Febr. 2011, pp. 13 - 25.

Rorty, Richard. Contingency, Irony and Solidarity. CUP, 1989. 